\title{
Model-instrumental Means for Research of Critical Energy Infrastructure
}

\author{
Natalia Pyatkova \\ Melentiev Energy Systems Institute of Siberian \\ Branch of the Russian Academy of Sciences \\ Irkutsk, Russia \\ nata@isem.irk.ru
}

\author{
Natalia Beresneva \\ Melentiev Energy Systems Institute of Siberian \\ Branch of the Russian Academy of Sciences \\ Irkutsk, Russia \\ nata@isem.irk.ru
}

\begin{abstract}
The article presents the possibility of research the fuel and energy complex that unites the sectoral energy systems as a critical infrastructure in terms of energy security. The developed models for research taking into account the dynamics, a tool for calculating and analyzing the states of the fuel and energy complex in the context of a critical infrastructure are
\end{abstract}

Keywords - critical infrastructure, energy security, fuel and energy complex, energy systems, critical objects, package of applied programs

\section{INTRODUCTION}

Research of critical infrastructures under a high level of information technologies development have become one of the new directions of reliable energy supply research.

Abroad, studies of critical infrastructures began in the 90s of the last century [1-3], research centers have been established.

At the same time, the terminology on critical infrastructures is currently not settled. In particular, in [4] critical is understood to be "infrastructure, the elements of which are of particular importance for the state and society, failure or limitation of efficiency of which would lead to long disruptions in supply, serious violations of public security or other dramatic consequences" In accordance with this definition, the sectoral energy systems (SE) and the fuel and energy complex (FEC) can be certainly regarded to critical infrastructures, since the FEC is an interconnected infrastructure consisting of separate energy systems. This is confirmed by the importance of these structures for the economy of the state and society and is a major part of research on the energy security of the country.

\section{RESEARCH OF CRITICAL ENERGY INFRASTRUCTURES IN TERMS OF ENERGY SECURITY}

The energy security (ES) of the country and its regions is essentially a balance between energy demand and it's supply [5]. The main tasks for the study of energy security problems are the following:

- forecasting the conditions of energy systems (SE, ie critical infrastructures) and fuel and energy complex (complex consisting of critical infrastructures) functioning and development, taking into account possible emergency situations (critical and emergency situations);
- assessment of the energy systems condition in these conditions, identification of potential critical objects $(\mathrm{CO})$ in them;

- selection of possible directions and measures to prevent or reduce the negative impact of contingencies, taking into account specialized safety means (capacity reserves and fuel reserves), as well as the capabilities of the SE in critical or emergency situations (partitioning of systems for localization in accident, regulation power consumption, disconnection of individual consumers, etc.).

Researches of critical energy infrastructures from the ES standpoint are carried out within the framework of computational experiments based on the information base presented by the technical and economic characteristics of energy objects, reporting data on the state of energy systems, and the results of research about the development of the fuel and energy complex. These studies are based on the territorialproduction models of the fuel and energy complex, reflecting the technological cycle of energy resource transformations that simulate the operation of key energy objects under given operating conditions, as well as network flow models. The main research tool is information support programs of modeling perspective states in emergency situations, with next calculation and estimate of these states. An important component of the states assessment is the finding of potential critical objects, the determination of the degree of their criticality. Critical objects in this case are the most vulnerable elements of critical infrastructures, failures in the operation of which can cause significant disruptions in reliable energy supply to consumers. Therefore, when finding the critical objects in the fuel and energy complex, the conditions for the maximum possible satisfaction of consumers should be taken into account in the event of emergency situations implementation, related to the implementation of natural and technogenic threats. In case of natural threats, deviations of the maximum seasonal heating loads of the regions are possible depending on their climatic conditions, on the composition of consumers in them up to 20-30\%. Also, deviations can be accompanied by a significant increase in demand for energy resources for both the single climatic zone and several neighboring regions. 
Technogenic threats are the most critical for the gas industry and the power industry. In the gas supply system, one of the most dangerous factors is the possibility of damaging transcontinental gas pipelines coming from a large gas producing region through the Urals to the European part of Russia. In the electric power industry, significant shortages can be caused by disconnections between individual power systems or emergencies at specific power plants (for example, the Sayano-Shushenskaya HPP accident in 2009, the system accident at the power facilities of the SFO due to a failure at the Bratsk hydropower plant in June 2017).

To estimate the functioning of systems under these conditions can possible within the framework of stepby-step model studies based on industry models and models of fuel and energy complex functioning using the apparatus of dual assessments [6]. Dual estimates in this case can serve as a measure of the resource scarcity, show changes in the value of the objective function when the restriction of this resource is changed by one [7]. In our case, such a resource may be the production capabilities of the technological methods under consideration (capacity for extraction, production, transportation of energy resources, stocks for different purposes). Potential critical objects in this case will have negative values of dual variables, the ranking of which will lead to identification of the most critical industry objects. A general scheme of critical energy infrastructures studies using models from the standpoint of providing ES is shown in fig. 1.

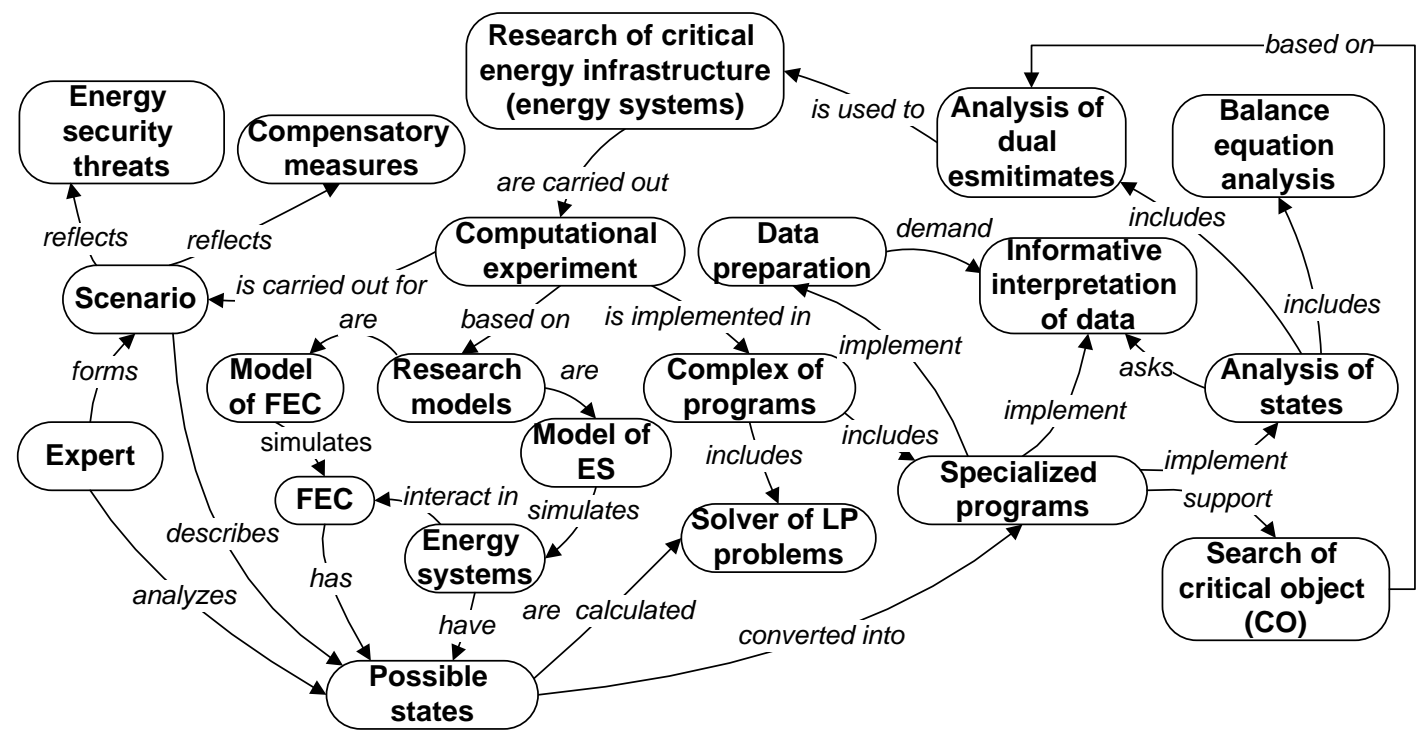

Fig.1 - Scheme of the critical energy infrastructures researches using models.

\section{THE SYSTEM OF ECONOMIC-MATHEMATICAL MODELS FOR RESEARCH OF CRITICAL ENERGY INFRASTRUCTURES WITH ACCOUNTING OF ENERGY SECURITY}

A review of the foreign researchers work on the modeling of critical infrastructures showed that these models have features that allow them to be applied only for these countries [8].

At present, a large number of models [9] have been developed in foreign countries for the study of ship systems, campuses, large electricity distribution networks, waterways and much more, and their main task has been to integrate them into a single hardware and software system that will provide managers with appropriate the ability to make an informed and correct decision, getting a reply to the question "what needs to be protected or hit and how much it will cost (spend ie the efforts and resources)".

Therefore, to study the behavior of Russia's critical energy infrastructures, original models for these studies were proposed.

Assessment of abnormal situations consequences in energy systems requires a special analysis of the critical infrastructures behavior (Energy Systems) near their limiting condition, possible only in case of consistent hierarchy FEC and SE. Only this scheme will allow to coordinate the results of the functional properties studies for the individual energy systems and structural relation in the energy sector, will allow to consider together the physical and technical and economic characteristics of the objects. In this case, in fact, two problems are solved:

- the task of allocating potential CO for the functioning of energy systems in abnormal situations;

- the task of estimate the extent of critical object's impact on the fuel and energy sector functioning under the potential threats to ES.

These tasks are being solved within the framework of the joint use of models for the functioning of energy systems and fuel and energy complex, different in the territorial, temporal and technological hierarchy [10]. Models of the fuel and energy complex functioning in this case provide a comprehensive assessment of the sectoral systems interconnected work, realize the search for the required volumes of energy supply (X), 
taking into account the given production capacity (matrix A) and energy consumption (B). At the same time, the requirement to minimize production costs $(\mathrm{Cx})$ and penalties (damages) for unsatisfied demand $(\mathrm{Sd})$ is observed.

$$
\begin{aligned}
& C x+S d \rightarrow \min \\
& A x-B \cdot(1-d)=0
\end{aligned}
$$

The evaluation of the individual energy systems functioning is solved using flow models in which the maximum flow task is solved, the criterion of the flows optimal distribution is the minimum of the energy resource deficit in the consumer with minimum costs for the production of energy resources and its delivery to consumers

$$
\max f
$$

$$
x_{i j}-\sum_{i \in N_{j}} x_{i j}=\left\{\begin{array}{c}
-f, j=0 \\
0, j \neq O, S \\
f, j=S
\end{array}\right.
$$

$$
\sum_{(i, j)} C_{i j} x_{i j} \rightarrow \min
$$

The listed models are conceptually identical. They are represented by a multitude of fuel and energy resources, a multitude of facilities (energy and economic-organizational) and a multitude of territorial units. The objects of the models are described by technological and economic characteristics, the processes (technologies) of resources conversion that take place in them. The interaction of objects, their association into groups and their territorial binding in the models is regulated by manage and organization links, applicable, including, to territorial units.

The joint consideration of such multi-level models makes it possible to determine the critical objects for individual energy systems and for the fuel and energy sector as a whole (fig. 2).

At the same time, not every critically important industrial object can be critical for the fuel and energy sector as a whole. This fact is explained by the availability of mechanisms to compensate for the shortage of energy resources under of the energy system interconnected work, including through the diversification

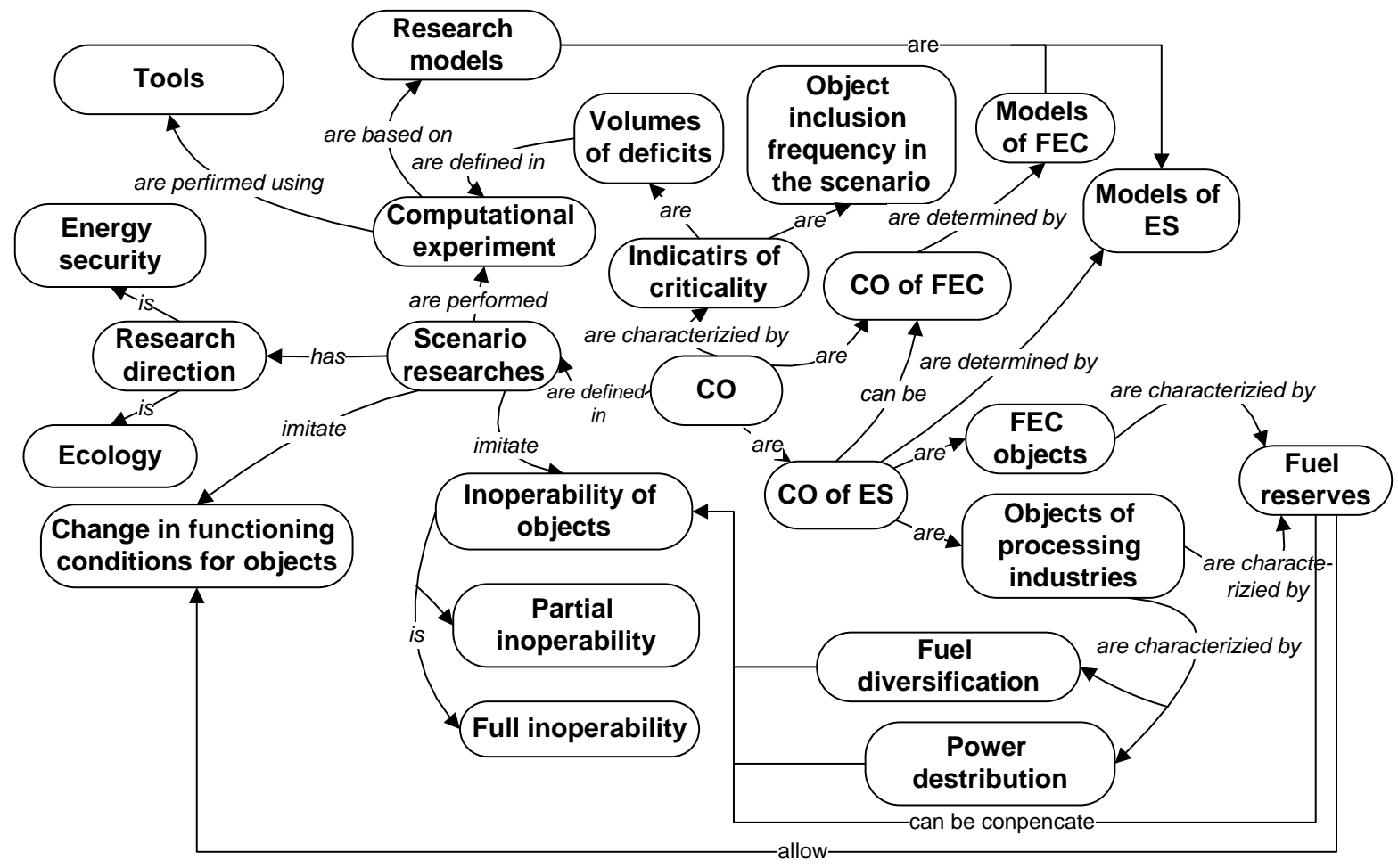

Fig.2 - Scheme for coordinating the selection of critical objects for critical infrastructures

of resources and the redistribution of the facilities' capacities. A comprehensive analysis of the objects criticality in the fuel and energy sector is carried out in the framework of the territorial-production models of the fuel and energy complex. The identification of the critical objects, in turn, is performed on the basis of the energy systems functioning models themselves.
Criticality of objects in both cases is mainly characterized by consumer deficits. In this case, the frequency of manifestation of the inoperability of objects in scenarios of contingencies can be taken into account. Mainly, such consistency in the finding of multilevel critical objects is explained by such factors as: 
- interchangeability of primary energy resources (gas, oil, coal, hydro and nuclear energy) in the production of secondary resources;

- interchangeability in means of energy resources transport, various types of energy resources among consumers;

- the possibility of FEC individual components mutual assistance in the development of management decisions towards different time period;

- the interdependence of regimes in the joint functioning of SE.

At the same time, the phased use of sectoral models and models of the fuel and energy complex supposes:

- - the consistency of temporal and territorial aspects in the allocation of the SE critical objects and the FEC critical objects;

- - consistency of changes in the indicators of energy objects functioning at various levels of research;

- - accounting of technical and technological abnormal conditions of the facilities functioning at both levels of research.

The methodology for finding the critical objects for individual industries and for the fuel and energy complex as a whole can differ in terms of the objects composition, criteria for assessing their criticality. But in any case, the following provisions will occur:

1. Finding of the critical objects includes identification of objects for interconnected energy systems, requires analysis of the contingency situations consequences on the selected objects, the choice of invariant measures to neutralize the consequences of these contingency. Invariance of measures is determined by the frequency of their application to eliminate the consequences of the found critical objects inoperability.

2. When identifying the critical objects, the uniqueness of the energy objects composition takes place. The identification of the critical objects is carried out with the help of specialized criteria, it is regulated by expertly established admissible values of these criteria. Criteria can be applied to individual types of critical objects, or to all objects at once. The criteria are calculated based on the obtained information from model. The key criterion for assessing critical objects is the relative total shortage of energy resources with threshold of relative deficit, which an expert is established.

3. The identification of different critical objects can be carried out expertly on the basis of a calculation results collection (in the "manual" mode), or using specialized algorithms for converting the results of calculations ("comlex" identification mode).

4. The ranking of the critical objects by significance is based on the selection criteria used, taking into account the composition of the invariant measures to eliminate the consequences of the reduction in the operability of the objects.

5. The determining factor is the assessments of experts on the basis of which scenarios are formed and the results of contingencies are assessed, the effectiveness of measures to eliminate the consequences of these situations.

The key steps in determining the critical objects of the FEC are shown in Fig.3.

\section{INFORMATION SUPPORT FOR RESEARCH}

Information support for research on fuel and energy complex models is implemented in a distributed package of applied programs (PAP)"Corrective" [11], used for the analysis of reliable fuel and energy supply in conditions of critical energy infrastructures work. This package implements universal mechanisms for the formation of FEC states, unified algorithms for their analysis with a customizable choice of evaluation criteria, identification of potential COs based on dual estimates. The PAP consists of four software modules, one of which ("universal") can be used as an independent research tool in the local computing mode. In general, the "Corrective" is characterized by the following key provisions:

1. The PAP is intended for research into the development and functioning of the fuel and energy complex, and is oriented towards the use of the balance FEC territorial-production models. The main task of "Corrective" is to search for optimal states and directions for the development of the fuel and energy complex that are acceptable by the criteria determined by the specifics of the research.

2. The PAP is oriented to the distributed calculations of the FEC states, it can be used in the conditions of local calculations. The nature of the calculations depends on the purpose of the research, on the requirements for the set of formed states, assumes the use of different composition of program modules "Corrective ".

3. Distributed computing assumes the automatic creation of all possible FEC states for specified situations, require the use of a full package of programs, as well as an external tool for organization of distributed computing (the tool complex "DISCOMP", ORLANDO [12]). The interaction of these instruments is implemented at the level of the formed packages of FEC states.

4. Objects representing the states of the fuel and energy sector in the PAP are time-oriented graphs of two types:

- the graph of the FEC basic states with balanced states, set by scenarios of researches;

- automatically created graphs of the FEC development with different sets of states (this is the calculated graph of the FEC development, a sparse graph of the FEC permissible states). 


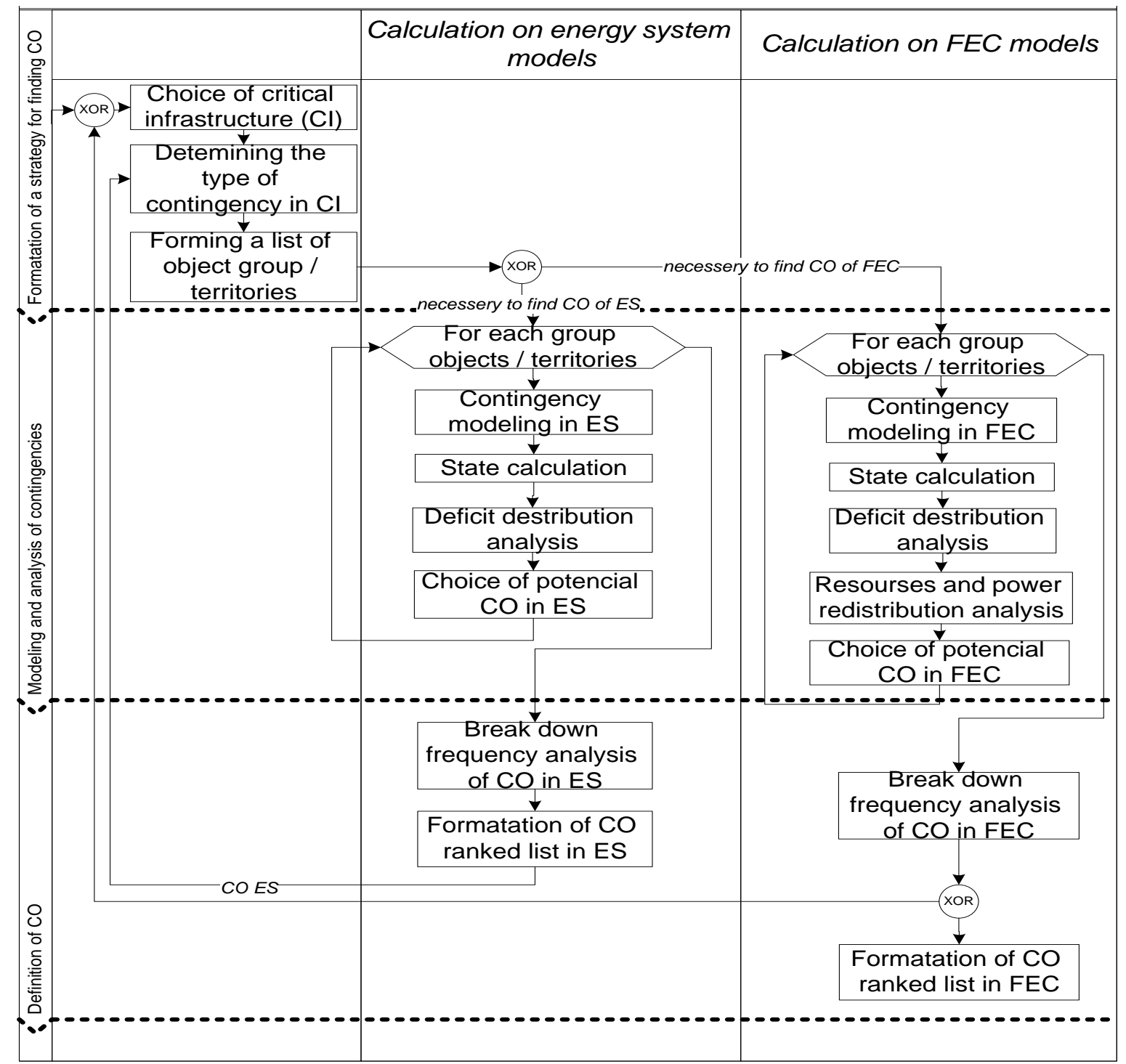

Fig.3 - Stages of determining the critical objects of the fuel and energy sector within the framework of two-level model studies.

5. Perturbing impacts (in the PAP) are specified using the graphs of the FEC development. Each such graph includes the coefficient of changing the boundaries of energy object parameter.

The main program modules " Corrective ":

- module for the formation the basic graph of the FEC development (the module 1);

- module for forming the graph of the FEC development (module 2);

- module for assessing the admissibility of the FEC state (module 3);

- expert evaluation module of the FEC admissible states graph (module 4).

Functional capabilities of these modules are used in different composition in different research schemes in relation to different types of energy development graphs. Within the framework of the PAP, the following research schemes have been implemented:
- researches of the FEC functioning with the generation of all possible states in the fuel and energy sector, followed by distributed calculation, analysis;

- researches of the FEC development in local and distributed variants of calculations.

\section{CONCLUSION}

The developed models were used in studies of critical energy infrastructures. The model and program tools presented in the article make it possible to carry out research to assess various contingencies in the fuel and energy complex and branch energy systems:

- to take into account interbranch relations in studies of energy security problems;

- for the assessment of the energy systems state and fuel and energy complex in contingency situations with different options for their development; 
- to identify restrictions on energy objects (transport, production, reserves, storage), which adversely affect the reliable fuel and energy supply of consumers.

Further development of the research assumes the adoption of a methodical device for identifying critical industry objects and fuel and energy complex objects that can significantly affect the reliable energy supply to consumers and conduct computer experiments on the basis of this apparatus.

\section{ACKNOWLEDGMENT}

The results were obtained in the framework of the project for state assignment of the ESI SB RA No. AAAA-A17-117030310451-0, some aspects were worked out in the framework of projects supported by the RFBR grant No. 19-07-00351.

\section{REFERENCES}

[1] . Executive Order. 13010. Critical Infrastructure Protection. Federal Register. Vol. 61. №. 138. July 17, pp. 3747-3750 (1996)

[2] Rinaldi S., Peerenboom J., and Kelly T. IEEE Control Systems Magazine, IEEE, December, pp. 11-25 (2001).

[3] Keating C., Rogers R., Dryer D., Sousa-Poza A. and other. Engineering Management Journal, 2003.Vol. 15, № 3 (2003).

[4] Protect critical infrastructure. The concept of basic protection measures [Electronic resource]. Access mode: https://www.google.ru/url?sa=t\&rct=j\&q=\&esrc=s\&source= web\&cd=1\&ved=0ahUKEwigkZ6K_PrSAhUCZCwKHfWB AuIQFggcMAA\&url=https\%3A\%2F\%2Fwww.bmi.bund.de $\% 2$ FSharedDocs $\% 2$ FDownloads\%2FDE\%2FBroschueren $\% 2$ FSprachvarianten\%2FBasisschutzkonzept_kritische_Infrastru kturen_russisch.pdf\%3F blob\%3DpublicationFile\&usg=AF QjCNEjmCRfUtwKQGtk9uxHwqHBquPANA\&sig2=fS5ph QcKNaE41QBH_qSuQ\&cad=rjt

[5] Energy security of Russia: problems and solutions / N.I. Pyatkova [et al.], Ed. N.I. Voropay, M.B. Cheltsov;, Energy
Systems Institute RAS SB. - Novosibirsk: SB RAS Publishing House, 2011. - 198 p [Energeticheskaya bezopasnost' Rossii: problemy i puti resheniyaб Institut sistem Energetiki RAN, Novosibirsk, Izdatel'skij dom RAN, 2011, 198] (In Russian)

[6] Zorkaltsev V.I. Methods for forecasting and analyzing the efficiency of the fuel supply system. - Moscow: Nauka, 1988. - $144 \mathrm{p}$ [Metody prognozirovaniya i analiza effektivnosti funkcionirovaniya sistemy toplivosnabzheniya, Moskva, Nauka, 1988, 144] (In Russian)

[7] Sakovich V.A. Optimal solutions to economic problems. Minsk: Higher Education school, 1982. - 272 p. [Optimal'nye resheniya ekonomicheskih zadach, Minsk, Vysshaya shkola, 1982, 272] (In Russian)

[8] Dunn M., and Wigert I.. International CUP Handbook, An Inventory and Analysis of Protection Policies in Fourteen Countries. (Swiss Federal Institute of Technology, Zurich ,2004).

[9] Dudenhoeffer D. D., Permann M. R., and Manic M., Submitted to Proceedings of the 2006 Winter Simulation Conference, pp. 478-485 (2006)

[10] System research in the energy sector: Retrospective of scientific directions SEI-ISEM / Ed. N.I. Voropay. Novosibirsk: Nauka, 2010. 686 p. [Sistemnye issledovaniya v energetike: retrospektiva nauchnyh napravlenij SEI-ISEM, Novosibirsk, Nauka, 2010, 686] (In Russian)

[11] Edelev A.V., Beresneva N.M.. Features of model studies of the problem of ensuring energy security in Russia. Scientific Bulletin of the Novosibirsk State Technical University. №2 (67), 2017 - pp. 94-108 [Osobennosti model'nyh issledovanij problemy obespecheniya energeticheskoj bezopasnosti Rossii, Nauchnyj vestnik Novosibirskogo Gosudarstvennogo Tekhnicheskogo Universiteta, №2(67), 2017，94-108] (In Russian)

[12] A Feoktistov A., Gorsky S., Sidorov I., Kostromin R., Edelev., Massel L. Orlando Tools: Energy Research Application Development through Convergence of Grid and Cloud Computing // Communications in Computer and Information Science. 2019. Vol. 965. P. 289-300. 